\title{
PERAN UKM DALAM MEMPOSISIKAN PRODUK KHAS DAERAH MELALUI MANAJEMEN IMAGE DI ERA PERSAINGAN GLOBAL
}

\author{
Wiwik Maryati \\ Universitas Pesantren Tinggi Darul Ulum \\ Email korespondensi:wima08@ymail.com
}

\begin{abstract}
This study aimed to investigate the role of SMEs on local product positioning through image management in this current global competitive era. SME's have played a role, particularly to local products to be globally well recognized as featured products. Jombang is one of region in East Java which has a lot of SMEs that has successfully produced various local products such as foods, beverage, handycrafts, and batik. For this far, a lot of their products have widely reached customers across the globe. However, some people remain unfamiliar with those local products, since many of the SME's did their marketing indirectly. Therefore, it needs a management of image to build valuation and gain customers' trust entirely. This present study applied a qualitative approach with case study as its research method by examining the conditions of SME's in Jombang. The result showed that the SME's played their role in positioning various local products in this current global competitive era through a management of image, both in brands and the SMEs. The management of image was conducted by communicating the marketing through various media, both electronic and non-electronic ones, in order to get better understanding about consumers. This present study, however, has limitation on the number of the entrepreneurs selected as the participants of this research. Thus, it is interesting for further studies to conduct their researches not only on limited particular enterprises, but more.
\end{abstract}

Keywords: SMEs, positioning, local products, management of image, global competition

Received: 31 Januari 2018

Reviewed: 21 Pebruari 2018

Accepted: 24 April 2018

Published: 26 April 2018

\section{PENDAHULUAN}

Era globalisasi menjadikan masyarakat dari negara-negara di dunia ini saling berkompetisi untuk meningkatkan berbagai aspek seperti ekonomi, hukum, politik, sosial budaya maupun pertahanan dan keamanan. Fokus utama yang dibutuhkan pada era yang penuh persaingan ini adalah pada bagaimana nantinya negara-negara yang ada bisa berdaya saing dengan mengandalkan aspek-aspek yang dapat dikomparasikan baik aspek sumber daya alam (SDA), sumber daya manusia (SDM) maupun aspek geografis. Aspek ekonomi merupakan aspek 
utama yang menjadi fokus dari kesepakatan antar negara, dimana salah satu hal yang menjadi sasaran dalam peningkatan ekonomi adalah bagaimana membuat produk yang mempunyai nilai tinggi dan mampu berdaya saing. Perusahaanperusahaan dituntut untuk dapat melakukan kegiatan yang dapat menambah added value dan keunggulan dari kondisi saat ini. UKM telah terbukti memberikan kontribusi peningkatan perekonomian melalui perannya dalam menciptakan produk khas daerah.

Agar produk khas daerah mampu bersaing di era global, keberadaan UKM berperan penting dalam memposisikan produk khas daerah tersebut agar mudah dikenal masyarakat secara global. Peran UKM ini terlihat pada upaya yang telah dilakukan dalam pemanfaatan teknologi untuk aktivitas pemasaran yang berupa $e$ marketing. Aktivitas e-marketing inilah yang nantinya diharapkan lebih memudahkan proses mengedukasi masyarakat sehingga upaya menempatkan posisi produk di benak masyarakat juga lebih mudah. Manhas (2010) dan Karadeniz (2009) dalam penelitiannya sudah membuktikan bahwa perusahaan agar dapat bersaing dengan perusahaan lain harus menciptakan sesuatu yang lebih unggul dari pesaing dengan memposisikan produk yang dapat melekat di benak konsumen. Ini menunjukkan betapa pentingnya peran UKM dalam positioning produk.

Produk khas daerah ini nantinya dijadikan sebagai keunggulan suatu daerah/kota. Jombang adalah salah satu kabupaten yang ada di propinsi Jawa Timur dan cukup banyak juga UKM yang ada di kabupaten Jombang yang telah menghasilkan produk khas daerah. Produk khas daerah yang telah dihasilkan oleh kabupaten Jombang mulai dari makanan, minuman, kerajinan tangan sampai pakaian batik khas Jombangan. Keseluruhan produk khas Jombangan tersebut seringkali didapatkan tidak hanya di tempat produk tersebut dibuat (perusahaan) tetapi juga di toko pusat oleh-oleh khas Jombang maupun di beberapa toko di kota Jombang. Sejauh ini cukup banyak produk khas daerah yang dibuat para pengusaha UKM di kota Jombang dan sudah dinikmati oleh konsumen dunia. Namun masih ada masyarakat yang tidak mengetahui produsen sesungguhnya dari produk tersebut karena tidak semua UKM memasarkannya secara langsung. Ada juga UKM yang membuat saja sedangkan untuk pemasarannya dilakukan oleh perusahaan lain. Lebih parahnya lagi pihak pembuat produk yaitu si pelaku UKM ada juga yang tidak mampu mengingat produk-produk apa saja yang sudah pernah dibuat maupun yang sudah dikembangkan karena belum menggunakan manajemen arsip sebagaimana mestinya.

Masyarakat tidak tahu itu produk siapa karena lemahnya UKM dalam melakukan penetapan posisi (positioning) produk khas daerah. Positioning ini dapat dilakukan dengan manajemen image yang bertujuan untuk membangun penilaian dan mendapatkan kepercayaan dari konsumen secara menyeluruh. Berdasarkan fenomena maupun konsep di atas, artikel ini berupaya mengkaji peran UKM dalam memposisikan produk khas daerah melalui manajemen image 
di era persaingan global. Strategi positioning ini dilakukan dengan membangun manajemen image pada merek (produk) maupun UKM (corporate) untuk memberikan pengetahuan dan pemahaman pada masyarakat.

Penelitian sebelumnya cukup banyak yang mengkaji tentang peran UKM di era persaingan global, namun kebanyakan dikaitkan dengan manajemen inovasi bukan pada manajemen image (Tamayo, et al, 2014; Ndubisi, 2014). Penelitian Tamayo (2014) dan Ndubisi (2014) keduanya menunjukkan bahwa inovasi dapat meningkatkan daya saing baik produk maupun UKM itu sendiri. Begitu juga dengan penelitian tentang upaya perusahaan dalam memposisikan produk di benak konsumen juga sudah dilakukan dalam kajian penelitian sebelumnya (Manhas, 2010; Karadeniz, 2009). Baik penelitian Manhas (2010) dan Karadeniz (2009) keduanya membuktikan bahwa era globalisasi yang penuh dengan persaingan menuntut perusahaan-perusahaan dapat menciptakan sesuatu yang lebih dari pesaing dengan memposisikan produk yang dapat melekat di benak konsumen. Berdasarkan pada penelitian sebelumnya tersebut, penelitian ini mengambil celah dengan mengkaji peran UKM dalam memposisikan produk yang ditinjau dari manajemen image bukan manajemen inovasi.

Sebagaimana UU No 20 tahun 20008 jenis usaha yang ada di masyarakat dapat dikelompokkan ke dalam usaha mikro, kecil, menengah dan besar yang kesemuanya disebut sebagai dunia usaha. Dunia usaha sesuai undang-undang ini diartikan sebagai usaha mikro, usaha kecil, usaha menengah dan usaha besar yang melakukan kegiatan ekonomi di Indonesia dan berdomisili di Indonesia.

Untuk membedakan karakteristik dunia usaha sesuai UU No 20 tahun 2008 dijelaskan dalam tabel 1 berikut ini.

Tabel 1. Jenis Dunia Usaha di Indonesia Sesuai UU No 20 Tahun 2008

\begin{tabular}{lll}
\hline $\begin{array}{c}\text { Jenis Dunia } \\
\text { Usaha }\end{array}$ & \multicolumn{1}{c}{ Kekayaan Bersih } & Hasil Penjualan Tahunan \\
\hline \hline Usaha Mikro & Rp. 50.000.000 & Rp. 300.000.000 \\
\hline Usaha Kecil & Rp. 50.000.000-500.000.000 & Rp. 300.000.000-2.500.000.000 \\
\hline $\begin{array}{l}\text { Usaha } \\
\text { Menengah }\end{array}$ & Rp.500.000.000-10.000.000.000 & Rp.2.500.000.000-50.000.000.000 \\
\hline Usaha Besar & $>$ Rp. 10.000.000.000 & > Rp. 50.000.000.000 \\
\hline
\end{tabular}

Sumber: Dhewanto, dkk (2015:23)

Berdasarkan jenis usaha yang dijelaskan pada tabel 1 di atas, maka UKM tergolong pada jenis usaha kecil dan menengah. Usaha kecil adalah usaha ekonomi produktif yang berdiri sendiri, dilakukan orang perorangan atau badan usaha yang bukan merupakan anak perusahaan atau bukan cabang perusahaan yang dimiliki, dikuasai atau menjadi bagian baik langsung maupun tidak langsung dari usaha menengah atau usaha besar. Kriteria usaha kecil memiliki kekayaan bersih lebih dari Rp50.000.000-Rp500.000.000 tidak termasuk tanah dan bangunan tempat usaha. Usaha kecil memiliki hasil penjualan tahunan lebih dari Rp300.000.000-Rp2.500.000.000. Sedangkan usaha menengah didefinisikan 
sebagai usaha ekonomi produktif yang berdiri sendiri, yang dilakukan oleh perorangan atau badan usaha yang bukan merupakan anak perusahaan atau cabang yang dimiliki, dikuasai atau menjadi bagian langsung maupun tidak langsung dengan usaha kecil atau besar. Jumlah kekayaan bersih lebih dari Rp500.000.000Rp10.000.000.000 tidak termasuk tanah dan bangunan tempat usaha. Hasil penjualan tahunan lebih dari Rp2.500.000.000-Rp 50.000.000.000.

Telah dijelaskan pada bagian pendahuluan bahwa fokus era persaingan global dalam peningkatan aspek ekonomi adalah kemampuan dalam membuat dan memposisikan produk yang berdaya saing.Terdapat 2 hal yang harus difokuskan untuk mendefinisikan daya saing pada era persaingan ini, yaitu: 1) fokus pada aspek internal organisasi yang membuat daya saing, 2) fokus pada variabel yang secara langsung berhubungan pada pasar dan lingkungan organisasi. Opsi pertama, terkait dengan variabel internal organisasi yang didasarkan pada sumber daya. Pada perspektif ini penting untuk menganalisis sumber daya dan kapabilitas yang berkontribusi pada keunggulan kompetitif perusahaan. Opsi kedua, mendefinisikan atribut daya saing yang berperan penting pada pasar dan kemudian pada klien serta interaksi organisasi/perusahaan dengan perusahaan lainnya dan perusahaan dengan lingkungannya (Tamayo, et al, 2014).

Membangun manajemen image pada produk khas daerah pada kajian ini merupakan upaya UKM dalam berkontribusi di era persaingan global yang difokuskan pada aspek internal dengan tujuan agar produk UKM dapat melekat di benak masyarakat secara luas baik masyarakat Jombang sendiri, luar Jombang bahkan sampai luar negeri.

Terkait dengan konsep positioning, Karadeniz (2009) menyebutkan bahwa positioning merupakan pengembangan dari image produk secara langsung terhadap produk pesaing dan produk lainnya yang dihasilkan oleh perusahaan sendiri. Tujuannya adalah agar konsumen memberikan perhatian pada produk tersebut dibandingkan dengan produk lain yang sejenis. Positioning ini bukanlah apa yang dilakukan untuk produk, namun apa yang dilakukan untuk pikiran konsumen kedepannya atau menempatkan produk dalam pikiran konsumen. Memposisikan produk adalah cara dimana produk diartikan oleh konsumen sebagai atribut yang penting dan ditempatkan dalam pikiran konsumen diantara produk-produk pesaing (Soundararaj dan Rengamani, 2002). Positioning yang efektif sebagaimana dikatakan Manhas (2010) membutuhkan pesan yang ringkas, fokus dan konsisten. Analisis positioning membutuhkan pemahaman bagaimana merek dapat diterima untuk sebuah atribut yang dianggap penting pada target dan relatif untuk bersaing. Oleh karena itu positioning sebuah merek yang banyak atribut dan pasar yang heterogen untuk saat ini merupakan tantangan bagi perusahaan. Ada 2 implikasi penting dari teori positioning, yaitu: 1) atribut merek harus ditekankan pada saat positioning merek dalam pikiran segmen yang ditarget, 2) bagaimana strategi positioning dapat mengkounter pesaing. 
Oleh karena positioning bertujuan untuk mendapatkan penilaian konsumen, maka membangun pengetahuan produk memainkan peran penting dalam pengambilan keputusan konsumen. Pengetahuan konsumen ini tekait dengan 2 bentuk yaitu pengetahuan subyektif dan pengetahuan obyektif yang diukur dengan pertanyaan-pertanyaan informasi faktual tentang kesalahan (Kolyesnikova, et.al, 2008). Lebih lanjut Kolyesnikova, et.al (2008) mengatakan bahwa pengetahuan obyektif meliputi pengetahuan tentang produk yang terkait dengan terminologi, atribut produk, kegunaan produk dan masih banyak lagi. Semakin besar tingkat akurasi pengetahuan yang dipegang dalam memori seseorang, semakin besar pula tingkat pengetahuan obyektif. Sedangkan pengetahuan subyektif adalah penilaian konsumen sendiri pada tingkat pengetahuan produk. Konsumen dengan tingkat pengetahuan subyektif tinggi cenderung merasa perlu untuk sumber informasi dari luar dan dengan demikian akan lebih nyaman memilih tempat pembelian yang lebih mudah seperti pembelian virtual. Namun demikian konsumen dengan pengetahuan subyektif tinggi maupun rendah sering dengan mudah mengakses penilaian dan evaluasi melalui sumber web atau lainnya sebelum mereka memilih lokasi pembelian. Penggunaan sumber impersonal tersebut telah ditemukan berhubungan dengan tingkat pengetahuan subyektif (Dodd et.al, 2005).

Penjelasan tentang pengetahuan produk baik pengetahuan obyektif maupun pengetahuan subyektif di atas memberikan pemahaman bahwa membangun pengetahuan pada konsumen diarahkan pada upaya membangun ingatan konsumen pada produk yang terkait dengan terminologi, atribut, kegunaan dan karakteristik ekstrinsik dari produk seperti merek dan harga. Unsur-unsur yang seharusnya dibangun pada produk tersebut menuntut sebuah upaya penguatan manajemen image baik pada produk itu sendiri, merek maupun image perusahaan.

Terdapat dua komponen dasar untuk membangun image perusahaan menurut Nguyen dan LeBlanc (2002), yaitu (a) komponen fungsional yang berkaitan dengan komponen nyata (tangible), dimana komponen ini berkaitan dengan atribut yang dapat diukur dengan mudah; (b) komponen emosional yang berkaitan dengan faktor psikologis ditunjukkan melalui berbagai perasaan dan sikap konsumen pada perusahaan yang didasarkan pada pengalaman konsumen saat berinteraksi dengan perusahaan dan atribut informasi yang menggambarkan image perusahaan tersebut.

Bagian penting lainnya dari perusahaan dalam aktivitas pemasaran adalah mempertahankan image merek. Chaudhri \& Holbrook (2001) menyatakan bahwa merek dapat mempengaruhi respon positif dari konsumen setelah penggunaannya. Penelitian telah menunjukkan bahwa meningkatnya loyalitas merek terbangun karena pengaruh merek, namun secara bersamaan merek juga dianggap sebagai variabel utama yang menyebabkan menurunnya loyalitas (Ringberg dan Susan, 2003). Begitu pentingnya merek maka perlu dikelola dengan menjaga dan mempertahankan image-nya yang dikenal dengan manajemen image merek atau 
biasa disebut dengan manajemen konsep merek (Brand Concept Management/BCM).

\section{METODE PENELITIAN}

Penelitian ini menggunakan desain riset kualitatifdengan menganalisis peran UKM di era persaingan global dalam memposisikan produk khas daerah melalui manajemen image. Lokasi penelitian di kabupaten Jombang tepatnya pada UKMUKM yang sudah memproduksi produk khas Jombang. Subyek penelitian adalah pelaku UKM yang diambil secara representatif dari pelaku usaha produk makanan dan minuman, kerajinan tangan dan batik. Pengumpulan data dilakukan dengan cara observasi, interview dan dokumentasi. Teknik analisis data dalam penelitian ini menggunakan case study dengan langkah-langkah analisis data menurut Hesse dan Biber (2011:302-315) sebagai berikut: langkah 1: fase penyiapan data; langkah 2 dan 3: fase eksplorasi dan reduksi data; dan langkah 4: fase interpretasi.

\section{HASIL DAN PEMBAHASAN}

Jombang merupakan salah satu kabupaten dari 38 kabupaten di propinsi Jawa Timur yang terdiri dari 21 kecamatan. Berdasarkan data yang tercatat pada arsip Dinas Koperasi dan UMKM kabupaten Jombang, jumlah UMKM ada 33.037 dengan rincian usaha mikro 28.701, usaha kecil 4079 dan usaha menengah sebanyak 257. Namun UKM unggulan yang berhasil dipetakan oleh Dinas Koperasi dan UMKM kabupaten Jombang ada 50 UKM. Data UKM Unggulan di Kabupaten Jombang dapat dilihat selengkapnya di lampiran.

Berdasarkan informasi yang didapat dari pelaku UKM di kabupaten Jombang, diketahui bahwa para pelaku UKM melakukan positioning pada produk khas daerah dengan cara membangun manajemen image baik pada produk dan merek itu sendiri maupun image UKM. Mereka menyadari bahwa strategi pemasaran tidak langsung yang selama ini mereka lakukan melalui peran jejaring rekanan/partner usaha menjadikan konsumen lebih mengetahui perusahaan pemasar daripada UKM yang membuat. Para pelaku UKM lebih memilih cara ini karena mereka berpikir akan lebih baik mereka hanya sebagai pembuat produk sedang pemasaran diserahkan pada pihak rekanan agar tidak memerlukan biaya yang lebih besar.Merekapun bisa membangun relasi yang seluas-luasnya dengan perusahaan pemasar tidak hanya satu perusahaan saja.

Namun seiring berkembangnya waktu, para pelaku usaha juga mulai menyadari bahwa era globalisasi ini menuntut daya saing yang tinggi dengan nilai lebih yang harus dimiliki oleh perusahaan, maka UKM pun mulai berbenah untuk memperkuat posisinya dengan melakukan manajemen image. Manajemen image ini dilakukan tidak hanya memperkuat posisi UKM saja, melainkan juga posisi produk dan merek. Tujuannya agar tidak hanya perusahaan pemasar saja yang dikenal melainkan juga UKM yang memproduksi. Upaya yang dilakukan oleh 
UKM dalam mengelola image merek ini meliputi beberapa tahapan kegiatan, yaitu sebagai berikut.

\section{Tahap Pengenalan}

Pada tahap ini perusahaan mempertimbangkan bagaimana mengoperasionalkan manajemen konsep merek ini dengan menggunakan elemenelemen marketing mix.

\section{Tahap Elaborasi}

Pada tahap ini strategi memposisikan merek difokuskan pada peningkatan nilai image merek sehingga dapat diterima secara superior dalam hubungan dengan kompetitor. Perbaikan dan peningkatan pada nilai merupakan hal yang sangat penting dalam lingkungan yang penuh persaingan dan kompleks. Strategi positioning dalam hal ini diimplementasikan yang tentunya juga perlu dipertimbangkan dengan marketing mix. Melalui strategi positioning pada tahap elaborasi ini manajemen dapat menyampaikan image yang dinilai secara lebih dan membatasi image dari persaingan.

\section{Tahap Fortifikasi}

Tujuan tahap ini adalah untuk menghubungkan elaborasi image merek pada image produk yang lain yang diproduksi oleh perusahaan pada kelas produk yang berbeda. Hal ini dilakukan agar masing-masing produk tersebut dapat saling menguatkan satu dengan lainnya. Strategi penguatan pada fortifikasi ini bukan berarti menghentikan tahap elaborasi pada merek. Tahap elaborasi harus tetap dilanjutkan pada setiap kehidupan merek.

Upaya manajemen image ini dilakukan dengan komunikasi pemasaran baik melalui media non elektronik yaitu dengan mengadakan event-event (expo) maupun melalui media elektronik/e-marketingseperti web blog maupun facebook. Langkah UKM dengan strategi komunikasi pemasaran seperti ini telah menunjukkan bahwa UKM ikut berperan aktif di era persaingan global tidak hanya sekedar sebagai produsen saja, melainkan juga dalam memposisikan produk. Dampaknya masyarakat bukan hanya mengenal perusahaan pemasar saja, namun mulai mengenal UKM sebagai produsen produk khas daerah.

Hasil analisis yang menunjukkan bahwa untuk menghadapi persaingan di era global ini perusahaan dapat melakukan positioning produk agar melekat di benak konsumen telah mendukung penelitian Manhas (2010) dan Karadeniz (2009). Demikian pula upaya manajemen image dengan strategi komunikasi pemasaran telah menunjukkan kesesuaian sebagaimana yang disampaikan oleh Nguyen dan LeBlanc (2002). Komunikasi pemasaran merupakan bentuk komponen fungsional (tangible) dan emosional untuk membangun image perusahaan agar mendapatkan penilaian positif dari konsumen. Peran komunikasi pemasaran di sini adalah untuk memberikan pengetahuan tentang produk dan 
UKM pada konsumen sehingga nantinya konsumen mempunyai pemahaman yang baik.

\section{KESIMPULAN}

Berdasarkan hasil penelitian di atas menunjukkan bahwa di era globalisasi yang penuh dengan persaingan ini UKM telah berperan dalam memposisikan produk khas daerah melalui manajemen image. Peran UKM sebagai produsen dalam memposisikan produk khas daerah di era persaingan global harus mendapatkan perhatian agar masyarakat dapat mengenalnya. Image yang selama ini terkesan bahwa produk khas daerah adalah buatan perusahaan pemasar harus dihindari dengan melakukan manajemen image, baik image pada UKM maupun image pada produk (merek). Agar terbangun image tersebut UKM telah melakukan komunikasi pemasaran yang bertujuan untuk memberikan pemahaman pada masyarakat baik pemahaman tentang produk maupun UKM itu sendiri. Hasilnya masyarakat mulai mengenal dan mengetahui bahwa produsen produk khas daerah Jombang yang selama ini dipasarkan sampai ke luar negeri adalah pelaku UKM di Jombang sendiri. Penelitian ini mempunyai keterbatasan pada jumlah owner UKM yang dijadikan partisipan, sehingga akan lebih baik untuk penelitian selanjutnya dapat dikaji dengan menambah jumlah partisipan (sampel) yang lebih besar.

\section{REFERENSI}

Chaudhuri, A dan Holbrook, M.B. 2001. The Chain of Effects from Brand Trust and Brand Affect to Brand Performance: The Role of Brand Loyalty. Journal of Marketing. Vol 65(2): 81-93.

Dodd, et al. 2005. Differential Effects of Experience, Subjective Knowledge and Objective Knowledge on Sources of Information Used in Consumer Wine PurchaseVenue. Journal of Hospitality and Tourism Research. Vol 29(1): 319.

Dhewanto, W., dkk. (2015). Manajemen Inovasi Untuk Usaha Kecil dan Mikro. Bandung: Alfabeta.

Hesse, S.N. dan Biber. P.L. (2011). The Practice Of Qualitative Research. London: SAGE publication.

Jombang, Pemkab. Data UKM Unggulan Kabupaten Jombang. jombangkab.go.id. diakses tanggal 13 September 2017.

Karadeniz, M. 2009. Product Positioning Strategy in Marketing Management. Journal of Naval Science and Engineering. Vol 5(2): 98-110.

Kolyesnikova, et al. 2008. The Influence of Product Knowledge on Purchase Venue Choice: Does Knowing More Lead From Bricks to Clicks?. Supply Chain Forum An International Journal. Vol 9(2): 28-40. 
Manhas, P.S. 2010. Strategic Brand Positioning Analysis Through Comparison of Cognitive and Conative Perceptions. Journal Economy Finance Administration Science. Vol 15(29): 15-33.

Ndubisi, N.O.2014. Quality Performance of SMEs In A Developing Economy: Direct and Indirect Effects of Service Innovation and Entrepreneurial Orientation. Journal of Business and Industrial Marketing. Volume 29(6). Halaman 454-468.

Nguyen dan Leblanc. 2002. Contact Personnal, Physical Environment and Perceived Corporate Image of Intangible Services by New Clients. International Journal of Service Industry Management. Vol 13 (3/4).

Ringberg, T. dan Susan, G. 2003. The Importance of Understanding The Symbolic World of Customers in asymmetric Business to Business Relationships. Journal of Business and Industrial Marketing Special Issue on Qualitative Approaches in B-2-B. Vol 18 (6): 607-626.

Soundararaj, J.J and Rengamani, J. 2002. The Inevitability of Positioning in The Present Marketing Scenario. Indian Journal of Marketing. Vol 32: 3-5.

Tamayo, J.A, et.al.2014. Do Innovation and Cooperation Influence SMEs Competitiveness? Evidence From The Andalusian Metal-Mechanic Sector. Innovar Journal. Volume 25(55). Halaman 101-115. 


\section{Lampiran 1. UKM Unggulan Kabupaten Jombang}

\begin{tabular}{|c|c|c|c|c|c|c|c|}
\hline No & Nama UKM & Komoditi & $\begin{array}{l}\text { Pangsa } \\
\text { Pasar }\end{array}$ & No & Nama UKM & Komoditi & $\begin{array}{c}\text { Pangsa } \\
\text { Pasar }\end{array}$ \\
\hline 1 & UD Prima & Genteng & $\begin{array}{l}\text { Lokal, } \\
\text { regional, } \\
\text { nasional }\end{array}$ & 26 & $\begin{array}{l}\text { UD Arifa } \\
\text { Souvenir }\end{array}$ & Fiber glass & $\begin{array}{l}\text { Lokal, } \\
\text { regional }\end{array}$ \\
\hline 2 & $\begin{array}{ll}\text { UD } & \text { Putri } \\
\text { Diana } & \end{array}$ & Sepatu & $\begin{array}{l}\text { Lokal, } \\
\text { regional, } \\
\text { nasional }\end{array}$ & 27 & $\begin{array}{l}\text { UD Barokah } \\
\text { Bordir }\end{array}$ & Bordir & $\begin{array}{l}\text { Lokal, } \\
\text { regional, } \\
\text { nasional }\end{array}$ \\
\hline 3 & UD Renyah & $\begin{array}{l}\text { Krupuk } \\
\text { krecek }\end{array}$ & $\begin{array}{l}\text { Lokal, } \\
\text { regional, } \\
\text { nasional }\end{array}$ & 28 & UD Barokah & Sepatu & $\begin{array}{l}\text { Lokal, } \\
\text { regional, } \\
\text { nasional, } \\
\text { ekspor }\end{array}$ \\
\hline 4 & UD Rochma & Jagung & Lokal & 29 & $\begin{array}{l}\text { UD Beads } \\
\text { Flower }\end{array}$ & $\begin{array}{l}\text { Manik- } \\
\text { manik kaca }\end{array}$ & $\begin{array}{l}\text { Lokal, } \\
\text { regional, } \\
\text { nasional, } \\
\text { ekspor }\end{array}$ \\
\hline 5 & $\begin{array}{ll}\text { UD } & \text { Sadar } \\
\text { Tani } & \end{array}$ & $\begin{array}{l}\text { Benih padi } \\
\text { \&beras }\end{array}$ & $\begin{array}{l}\text { Lokal, } \\
\text { regional, } \\
\text { nasional, } \\
\text { ekspor }\end{array}$ & 30 & $\begin{array}{l}\text { UD Sentral } \\
\text { Of Bronzes }\end{array}$ & $\begin{array}{l}\text { Cor } \\
\text { kuningan }\end{array}$ & $\begin{array}{l}\text { Lokal, } \\
\text { ekspor }\end{array}$ \\
\hline 6 & $\begin{array}{ll}\text { UD } & \text { Saifi } \\
\text { Jaya } & \end{array}$ & $\begin{array}{l}\text { Sepatu } \\
\text { sandal }\end{array}$ & $\begin{array}{l}\text { Lokal, } \\
\text { regional, } \\
\text { nasional }\end{array}$ & 31 & $\begin{array}{l}\text { UD Gajah } \\
\text { Mada }\end{array}$ & $\begin{array}{l}\text { Cor } \\
\text { kuningan }\end{array}$ & $\begin{array}{l}\text { Lokal, } \\
\text { regional, } \\
\text { nasional }\end{array}$ \\
\hline 7 & $\begin{array}{ll}\text { UD } & \text { Say } \\
\text { Mebel } & \end{array}$ & Meubeler & $\begin{array}{l}\text { Lokal, } \\
\text { regional }\end{array}$ & 32 & UD Ganesha & $\begin{array}{l}\text { Cor } \\
\text { kuningan }\end{array}$ & $\begin{array}{l}\text { Lokal, } \\
\text { regional, } \\
\text { nasional, } \\
\text { ekspor }\end{array}$ \\
\hline 8 & $\begin{array}{l}\text { UD } \\
\text { Sejahtera }\end{array}$ & Meubeler & $\begin{array}{l}\text { Lokal, } \\
\text { regional }\end{array}$ & 33 & $\begin{array}{ll}\text { UD } & \text { Hansa } \\
\text { Putra } & \\
\end{array}$ & Kecap & $\begin{array}{l}\text { Lokal, } \\
\text { regional }\end{array}$ \\
\hline 9 & $\begin{array}{ll}\text { UD } & \text { Sekar } \\
\text { Arum } & \end{array}$ & $\begin{array}{l}\text { Keripik } \\
\text { tempe }\end{array}$ & $\begin{array}{l}\text { Lokal, } \\
\text { regional }\end{array}$ & 34 & $\begin{array}{l}\text { UD Intan } \\
\text { Selatan }\end{array}$ & Batu onix & $\begin{array}{l}\text { Lokal, } \\
\text { regional, } \\
\text { nasional }\end{array}$ \\
\hline 10 & $\begin{array}{l}\text { UD Sekar } \\
\text { Jati Star }\end{array}$ & Batik & $\begin{array}{l}\text { Lokal, } \\
\text { regional, } \\
\text { nasional }\end{array}$ & 35 & $\begin{array}{l}\text { UD } \\
\text { Intazando }\end{array}$ & Dompet & $\begin{array}{l}\text { Lokal, } \\
\text { regional, } \\
\text { nasional }\end{array}$ \\
\hline 11 & $\begin{array}{l}\text { UD Setia } \\
\text { Kawan }\end{array}$ & Genteng & $\begin{array}{l}\text { Lokal, } \\
\text { regional, } \\
\text { nasional }\end{array}$ & 36 & $\begin{array}{l}\text { UD Java } \\
\text { Fiber }\end{array}$ & $\begin{array}{l}\text { Patung, } \\
\text { bros, } \\
\text { pigora, } \\
\text { acecoris }\end{array}$ & $\begin{array}{l}\text { Lokal, } \\
\text { regional, } \\
\text { nasional, } \\
\text { ekspor }\end{array}$ \\
\hline 12 & UD Shiwa & $\begin{array}{l}\text { Cor } \\
\text { Kuningan }\end{array}$ & $\begin{array}{l}\text { Lokal, } \\
\text { regional, } \\
\text { nasional, } \\
\text { ekspor }\end{array}$ & 37 & UD Jaya & $\begin{array}{l}\text { Kulit } \\
\text { wayang }\end{array}$ & $\begin{array}{l}\text { Lokal, } \\
\text { regional, } \\
\text { nasional }\end{array}$ \\
\hline 13 & UD Tata & $\begin{array}{l}\text { Manik- } \\
\text { manik kaca }\end{array}$ & $\begin{array}{l}\text { Lokal, } \\
\text { regional, } \\
\text { nasional, } \\
\text { ekspor }\end{array}$ & 38 & $\begin{array}{l}\text { UD Jenang } \\
\text { Kelapa } \\
\text { Muda }\end{array}$ & Jenang & $\begin{array}{l}\text { Lokal, } \\
\text { regional, } \\
\text { nasional }\end{array}$ \\
\hline 14 & UD Wisnu & $\begin{array}{l}\text { Cor } \\
\text { kuningan }\end{array}$ & $\begin{array}{l}\text { Lokal, } \\
\text { ekspor }\end{array}$ & 39 & $\begin{array}{l}\text { UD } \\
\text { Jati }\end{array}$ & $\begin{array}{l}\text { Wood } \\
\text { flooring, } \\
\text { garden } \\
\text { furniture, } \\
\text { indoor } \\
\text { furniture }\end{array}$ & $\begin{array}{l}\text { Lakal, } \\
\text { ekspor }\end{array}$ \\
\hline
\end{tabular}


BISMA (Bisnis dan Manajemen)

Volume 10 Nomor 2, April 2018

E-ISSN 2549-7790, P-ISSN 1979-7192

Halaman 134-144

\begin{tabular}{|c|c|c|c|c|c|c|c|}
\hline No & Nama UKM & Komoditi & $\begin{array}{c}\text { Pangsa } \\
\text { Pasar }\end{array}$ & No & Nama UKM & Komoditi & $\begin{array}{c}\text { Pangsa } \\
\text { Pasar }\end{array}$ \\
\hline 15 & $\begin{array}{l}\text { PT Mentari } \\
\text { Internasional }\end{array}$ & $\begin{array}{l}\text { Mainan } \\
\text { anak-anak }\end{array}$ & $\begin{array}{l}\text { Nasional, } \\
\text { ekspor }\end{array}$ & 40 & $\begin{array}{ll}\text { UD } & \text { Karya } \\
\text { Jati } & \end{array}$ & Meubelair & $\begin{array}{l}\text { Lokal, } \\
\text { regional, } \\
\text { Nasional }\end{array}$ \\
\hline 16 & $\begin{array}{l}\text { PT Semesta } \\
\text { Jati Indah }\end{array}$ & Lantai kayu & $\begin{array}{l}\text { Lokal, } \\
\text { ekspor }\end{array}$ & 41 & $\begin{array}{l}\text { UD Kurnia } \\
\text { Affandi }\end{array}$ & Sepatu & $\begin{array}{l}\text { Lokal, } \\
\text { regional, } \\
\text { Nasional } \\
\end{array}$ \\
\hline 17 & $\begin{array}{ll}\text { PT } & \text { Seng } \\
\text { Fong } & \end{array}$ & Lantai kayu & $\begin{array}{l}\text { Lokal, } \\
\text { ekspor }\end{array}$ & 42 & $\begin{array}{l}\text { UD Lima } \\
\text { Saudara }\end{array}$ & Bordir & $\begin{array}{l}\text { Lokal, } \\
\text { regional, } \\
\text { Nasional }\end{array}$ \\
\hline 18 & $\begin{array}{l}\text { PT Usmani } \\
\text { Indah }\end{array}$ & $\begin{array}{l}\text { Wood } \\
\text { Flooring }\end{array}$ & $\begin{array}{l}\text { Lokal, } \\
\text { ekspor }\end{array}$ & 43 & $\begin{array}{l}\text { UD } \quad \text { Lita } \\
\text { Bena }\end{array}$ & $\begin{array}{l}\text { Batik tulis, } \\
\text { printing }\end{array}$ & $\begin{array}{l}\text { Lokal, } \\
\text { regional, } \\
\text { Nasional }\end{array}$ \\
\hline 19 & $\begin{array}{ll}\text { UD } & \text { Abi } \\
\text { Mulya } & \end{array}$ & $\begin{array}{l}\text { Sepatu } \\
\text { sandal }\end{array}$ & $\begin{array}{l}\text { Lokal, } \\
\text { regional }\end{array}$ & 44 & $\begin{array}{l}\text { UD } \quad \text { Maju } \\
\text { Jaya }\end{array}$ & $\begin{array}{l}\text { Aluminiu } \\
\mathrm{m} \\
\text { batangan }\end{array}$ & $\begin{array}{l}\text { Lokal, } \\
\text { regional, } \\
\text { Nasional }\end{array}$ \\
\hline 20 & UD Agung & Meubelair & $\begin{array}{l}\text { Lokal, } \\
\text { regional }\end{array}$ & 45 & $\begin{array}{l}\text { UD Malik } \\
\text { Silver }\end{array}$ & $\begin{array}{l}\text { Kerajinan } \\
\text { perak }\end{array}$ & $\begin{array}{l}\text { Lokal, } \\
\text { regional, } \\
\text { Nasional }\end{array}$ \\
\hline 21 & UD Akas & $\begin{array}{l}\text { Pemecah } \\
\text { batu }\end{array}$ & $\begin{array}{l}\text { Lokal, } \\
\text { regional }\end{array}$ & 46 & $\begin{array}{l}\text { UDMulyafo } \\
\text { od Sumber } \\
\text { Sejahtera }\end{array}$ & $\begin{array}{l}\text { Makanan } \\
\text { ringan }\end{array}$ & $\begin{array}{l}\text { Lokal, } \\
\text { regional }\end{array}$ \\
\hline 22 & UD Amelido & Konveksi & $\begin{array}{l}\text { Lokal, } \\
\text { regional, } \\
\text { nasional }\end{array}$ & 47 & $\begin{array}{l}\text { UD Narda } \\
\text { Jati Jaya }\end{array}$ & Meubelair & $\begin{array}{l}\text { Lokal, } \\
\text { regional, } \\
\text { nasional }\end{array}$ \\
\hline 23 & $\begin{array}{l}\text { UD Andika } \\
\text { Souvenir }\end{array}$ & $\begin{array}{l}\text { Anyaman } \\
\text { bamboo }\end{array}$ & $\begin{array}{l}\text { Lokal, } \\
\text { regional, } \\
\text { nasional }\end{array}$ & 48 & UD Ning & Tas plastic & $\begin{array}{l}\text { Lokal, } \\
\text { regional, } \\
\text { nasional }\end{array}$ \\
\hline 24 & $\begin{array}{l}\text { UD Anggi } \\
\text { Souvenir }\end{array}$ & $\begin{array}{l}\text { Manik- } \\
\text { manik kaca }\end{array}$ & $\begin{array}{l}\text { Lokal, } \\
\text { regional, } \\
\text { nasional }\end{array}$ & 49 & $\begin{array}{l}\text { UD Nugraha } \\
\text { Fancy } \\
\text { Plywood }\end{array}$ & Plywood & $\begin{array}{l}\text { Lokal, } \\
\text { regional, } \\
\text { nasional, } \\
\text { ekspor }\end{array}$ \\
\hline 25 & $\begin{array}{ll}\text { UD } & \text { An } \\
\text { Nikmah } & \end{array}$ & $\begin{array}{ll}\text { Tas dan } \\
\text { dompet }\end{array}$ & $\begin{array}{l}\text { Lokal, } \\
\text { regional, } \\
\text { nasional }\end{array}$ & 50 & $\begin{array}{l}\text { UD Permata } \\
\text { Indah }\end{array}$ & $\begin{array}{l}\text { Manik- } \\
\text { manik kaca }\end{array}$ & $\begin{array}{l}\text { Lokal, } \\
\text { regional, } \\
\text { nasional }\end{array}$ \\
\hline
\end{tabular}

Sumber: Jombangkab.go.id 